\title{
Barcelona baby boom: does sporting success affect birth rate?
}

Nine months after a celebrated goal by FC Barcelona in 2009, the media reported a spike in the Catalan birth rate. Jesus Montesinos and colleagues test whether the "Iniesta effect" really existed

Jesus Montesinos head of research and innovation ${ }^{1}$, Jordi Cortes statistical researcher ${ }^{2}$, Anna Arnau epidemiologist ${ }^{1}$, Josep Anton Sanchez senior statistical lecturer ${ }^{2}$, Matt Elmore technical writer and editor ${ }^{3}$, Narcis Macia head of medical record service ${ }^{1}$, José Antonio Gonzalez associate statistical professor ${ }^{2}$, Ramon Santisteve gynecologist ${ }^{1}$, Erik Cobo associate statistical professor ${ }^{2}$, Joan Bosch director and professor of medicine ${ }^{14}$

\footnotetext{
${ }^{1}$ Althaia, Xarxa Assistencial Universitaria de Manresa, Barcelona, Spain; ${ }^{2}$ Department of Statistics and Operations Research, Universitat Politècnica de Catalunya, BarcelonaTech, Spain; ${ }^{3}$ Barcelona; ${ }^{4}$ Faculty of Medicine, Universitat Internacional de Catalunya, Barcelona
}

\section{Introduction}

On 6 May 2009, Andrés Iniesta scored a last minute goal against Chelsea FC, which put Football Club Barcelona (popularly known as Barça) in the UEFA Champions League final. This single goal was so emotive that the skies over Catalonia reverberated with fireworks, shouts of joy, and the banging of pots and pans. According to some media reports, many fans also celebrated by making other kinds of noise. Nine months after the event, Catalonia's COMRadio broadcast the results of an informal survey of five hospitals, which reported a $45 \%$ increase in the number of births. ${ }^{1-3}$ The putative cause of this spike in natality was Iniesta's breathtaking goal, and the children born during this boom came to be known popularly as "the Iniesta generation," implying that Iniesta had fathered-through surrogates_hundreds or even thousands of babies (fig $1 \Downarrow$ ).

Similar claims made by the media in the past have been disproved under scrutiny..$^{4-7}$ For example, the 1965 blackout in the northeast United States affected over 30 million people, including four million homes in New York City. Nine months after this event, the New York Times published four consecutive articles reporting a $30 \%$ increase in the birth rates of five hospitals in Manhattan. ${ }^{8}$ However, in 1970, Menaker et al ${ }^{6}$ showed that there had actually been a $20-25 \%$ decline in births rather than an increase. Nevertheless, some seasonal and social effects appear to be certain. We hope, for example, that it is not too late for the readers of this issue to bear in mind the
"Christmas effect," in which a sharp September spike appears nine months after the December holidays. ${ }^{9}$

We wondered if the Iniesta effect in Catalonia was real, and, if so, whether the exhilaration associated with football or other sporting events can truly have profound demographic repercussions.

\section{Methods}

We studied the counties of Solsones and Bages, which have a combined population of about 190000 (16.9\% children). ${ }^{10}$ This area is located in central Catalonia. Josep Guardiola, FC Barcelona's coach from 2008 to 2012, was born in this region (Santpedor, Bages, Jan 18 1971), so it seemed fair to assume that the population might have a heightened level of enthusiasm for Barça.

We used a time-trend ecological study design. As human pregnancy lasts 269 days, ${ }^{11}$ the target period was February 2010. The control period covered January 12007 to December 31 2011 (60 months). We looked at the number of births in two of Althaia Foundation's hospitals, located in Manresa, capital of Bages.

We analysed monthly birth data using time-series analyses to determine whether the observed changes in the target period were statistically significant. After seasonal differentiation the series was stationary, and an ARIMA model was fitted. 
Correlation was studied for the first 48 lags using autocorrelation and partial autocorrelation functions. The model selection was performed in accordance with the Akaike information criteria. To evaluate a possible abnormality in a specific period, a single covariate ("intervention") was included in the model under two different assumptions: (1) a one-time change modelled by using a covariate with zeros in all observations except a 1 in the pertinent month; and (2) a transitory change modelled by using a covariate with a value of 1 in the relevant month, which decreases exponentially over subsequent months by a factor of $0.7\left(1,0.7^{1}, 0.7^{2}\right.$, and so on). The value of 0.7 was chosen by following standard recommendations. ${ }^{12}$ To estimate the percentage increase, we applied a logarithmic transformation to the series.

The residuals of the final models were visually and statistically inspected to validate that they were normally distributed without auto-correlation (assessed by the Ljung-Box version ${ }^{13}$ of the portmanteau test) and that they had homogeneous variance. Finally, a standard methodology was implemented to automatically detect outliers. ${ }^{12}$ For sensitivity analysis, the absolute monthly numbers of births were adjusted to months of 30 days (years of 360 days) in order to normalise the unequal length of each month and the existence of leap years. The model fit and validation processes are provided in the supplementary appendix.

All tests had a two sided $\alpha$-penalty of 0.05 and were conducted using R statistical software version 2.15.0.

\section{Results}

The table $\Downarrow$ describes the study population. The average number of births per month was 183.3 (standard deviation 14.9; range $152-226)$. Figure $2 \Downarrow$ shows the number of births per month over time. A slight decrease in trend can be seen after mid-2010. September saw the most births and February the least. In 2010, the maximum births increased for both February and March in comparison with other years.

Of the two covariates we tested, representing one-time or transitory influence, the first failed to demonstrate statistical significance, but the second exhibited a significant and transitory increase following February 2010 (fig $3 \Downarrow$ ). The parameter related with this transitory change that minimised the Akaike information criteria was 0.73 , which was quite close to the standard chosen value. Figure $4 \Downarrow$ shows the model with the covariate intervention $\mathrm{I}_{\mathrm{t}}$.

The coefficient 25.8 (standard error, 8.9) of the covariate $I_{t}$ leads to a significant increase of 26 births in February 2010 and a slightly lower number in subsequent months. When we readjusted this model by employing logarithms, the percentage increment in births was $16.1 \%$ (95\% confidence interval 5.8 to 27.4 ) in February, with another $11.0 \%$ increase (4.0 to 18.5 ) in March.

\section{Discussion}

Our results show a transitory and significant $16 \%$ increase in births in February 2010, 9 months after FC Barcelona's exciting victories in May 2009-far short of the $45 \%$ increase reported by the media. We may infer that-at least among the target population-the heightened euphoria following a victory can cultivate hedonic sensations that result in intimate celebrations, of which unplanned births may be a consequence. Other studies ${ }^{14}{ }^{15}$ have shown, unsurprisingly, that rationality is not always a key factor in conception. One of the most intense emotions that can be experienced is the social component of belonging and the self assertion of a group ${ }^{16}$ (also known as you'll never walk alone). Thus, the act of coming together can be interpreted on many levels when people feel motivated to share their euphoria with others.

Some authors have shown that circumstances are decisive influences on human conception ${ }^{17}$ or other behaviours. ${ }^{18}$ Socioeconomic factors, wars, epidemics, famines, migrations, and cultural and religious events can drive or impede procreation every bit as much as candlelight with Julio Iglesias on the stereo, which - depending on the individuals present—could either enhance or reduce desire. Our results also show a decline in births from the second half of 2010, possibly caused by the Spanish economic crisis and presumably related to a decrease in "rational births." ${ }^{19}$ Positive emotional experiences appear to offset the pessimism produced by countries in crisis. ${ }^{20}$ To state it simply: bread and circuses may be a viable remedy for widespread dysphoria.

This study has several limitations, one of which is that the study design does not allow causal inferences. In fact, some of the authors (who happen to be Barça supporters: JM, JC, AA, NM, $\mathrm{RS}, \mathrm{JB}$ ), believe that an intense and brief stimulus (the Barça triumphs in May 2009) was the cause of the increase in births. The remaining authors (who, incidentally, are not Barça supporters) interpret that the term "Iniesta generation" is a misnomer. Those dissenting authors independently collected data from the Catalan Statistical Institute ${ }^{10}$ for the same period, and tested the Barcelona city population under the same hypothesis using the same methodology. But neither the same model nor the model which best fitted the data were able to replicate the effect: there was only a $1.2 \%$ increase $(95 \%$ CI -6.1 to 9.0). However, this does not invalidate the main results of our paper. One can easily argue that the Catalan regions do not belong to the same target population in terms of Barça support. In fact, the number of Barça supporters' groups compared with the number of groups supporting Real Madrid and RCD Español is higher in Bages-Solsones than in Barcelona City (odds ratio 1.21)..$^{21-23}$

In summary, our results may have several different interpretations. One is that human emotions on a large scale can profoundly affect demographic swings in populations, that national or regional events can reduce the weight of reason and increase the weight of passion. Validation of our results could contribute to a better understanding of human behaviour, improve healthcare planning, and even aid government policy makers in stimulating or reducing birth rates. Ideally, to bridge the gap between observational and trial data, it would help greatly if Iniesta were willing to replicate his intervention - although the cost of such a study could be prohibitive, not to mention harmful to the reference group (Chelsea).

Competing interests: The Barcelona team works close to the Barça stadium and admits to a risk of bias owing to the effects of the adjacent jubilation. The researchers from Solsones-Bages participated in the hypothesised intervention, but did not contribute to the observed effect.

Provenance and peer review: not commissioned; externally peer reviewed.

Marca.com. Guardiola: somos unos maquinas. 2010. www.marca.com/2010/01/29/futbol/ equipos/barcelona/1264782293.html.

Mundodeportivo.com. El Iniestazo aumenta la tasa de natalidad. 2010. www. mundodeportivo.com/20100127/el-iniestazo-aumenta-la-tasa-de-natalidad_53878987250. html.

3 RTVE.es. Los titulo del Barça provocan un baby boom. 2010. www.rtve.es/deportes/ 20100130/titulos-del-barca-provocan-baby-boom/315117.shtml.

4 Borst LB. Natality and the blackout. Am J Obs Gyn 1968:101:422-3.

5 James WH. Natality, Pearl Harbor, and the New York City blackout. Am J Obstet Gynecol 1971;111:1123-4. 
6 Menaker W. Evidence for a drop in conceptions in the big blackout. Am J Obstet Gynecol 1970;107:804-6.

7 Trail S, Borst LB. Pearl Harbor plus 268 days. Am J Obstet Gynecol 1971;109:1086-7.

New York Times. Births up 9 months after the blackout 1966. http://query.nytimes.com/ search/sitesearch/-/black+out+births/from19660101to19661231.

9 New York Times. With September's rains come baby showers. 1989. www.nytimes.com/ 1989/09/26/us/with-september-s-rains-come-baby-showers.html.

10 IDESCAT Catalan Statistics Institute. 2013. www.idescat.cat/en.

11 Smith GC. Use of time to event analysis to estimate the normal duration of human pregnancy. Hum Reprod 2001;16:1497-500.

12 Chen C, Liu LM. Joint estimation of model parameters and outlier effects in time series. Amer Statist Assoc 1993;88:284-97.

13 Ljung GM, Box GEP. On a measure of lack of fit in time series models. Biometrika 1978;65 297-303.

14 Krause EL. "They just happened": the curious case of the unplanned baby, Italian low fertility, and the "end" of rationality. Med Anthropol Q 2012;26:361-82.

15 Viero C, Shibuya I, Kitamura N, Verkhratsky A, Fujihara H, Katoh A, et al. Oxytocin: Crossing the bridge between basic science and pharmacotherapy. CNS Neurosci Therapeutics 2010;16:e138-56.

16 Neumann ID. The advantage of social living: brain neuropeptides mediate the beneficial consequences of sex and motherhood. Frontiers Neuroendocrinol 2009;30:483-96.
17 Rocca CH, Doherty I, Padian NS, Hubbard AE, Minnis AM. Pregnancy intentions and teenage pregnancy among Latinas: a mediation analysis. Perspectives Sexual Reproductive Health 2010;42:186-96.

18 Brimicombe ACR. Beware, win or lose: domestic violence and the World Cup. Significance 2012;9:32-35.

19 Goldstein J, Kreyenfeld M, Jasilioniene A, Orsal DK. Fertility reactions to the "Great Recession" in Europe: Recent evidence from order-specific data. Demographic research 2013;29:85-104.

20 Adler JM, Hershfield HE. Mixed emotional experience is associated with and precedes improvements in psychological well-being. PloS one 2012;7:e35633.

21 FC Barcelona. Supporters clubs. 2013. http://penyes.fcbarcelona.com.

22 RCD Español. Supporters clubs. 2013. www.rcdespanyol.com/principal.php? modulo=penyas\&nombremodulo $=$ penyes\&idlinkchk $=42$.

23 Real Madrid. Supporters clubs. 2013. www.realmadrid.com/cs/Satellite/es/Madridistas/ 1193040472660/Penias/Penas.htm.

Cite this as: BMJ 2013;347:f7387

C BMJ Publishing Group Ltd 2013 


\section{Table}

Table 1/ Characteristics of study group $(\mathbf{n}=\mathbf{1 1} 000)$

Median $\left(25^{\text {th }}\right.$ percentile to $75^{\text {th }}$ percentile) or number (\%)

\begin{tabular}{lc} 
Maternal age (years) & $31.5(27.9-34.6)$ \\
\hline Gestational weeks* & $39.0(38.0-40.0)$ \\
\hline Mode of delivery & $8026(73.0 \%)$ \\
\hline Vaginal & $2974(27.0 \%)$ \\
\hline Caesarean & $190(1.7 \%)$ \\
\hline Multiple birth & $3260(2940-3560)$ \\
\hline Birth weight of newborn $(\mathbf{g})$ &
\end{tabular}

*From the first day of a woman's last menstrual period. 


\section{Figures}

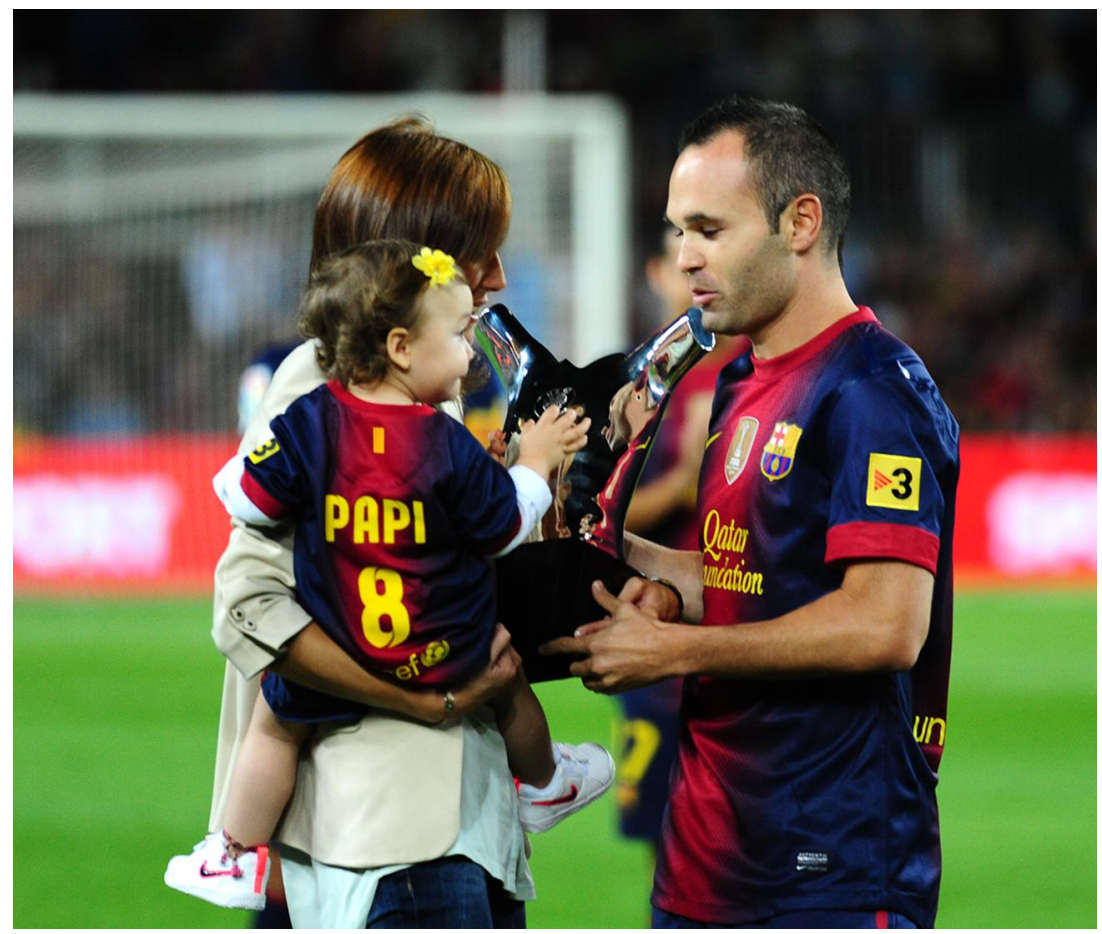

Fig 12 Sep 2012, Barcelona-Andres Iniesta is presented with his UEFA Player of the Year award before kick-off by his wife and daughter

[Image: Javier Garcia/BPI/Corbis]

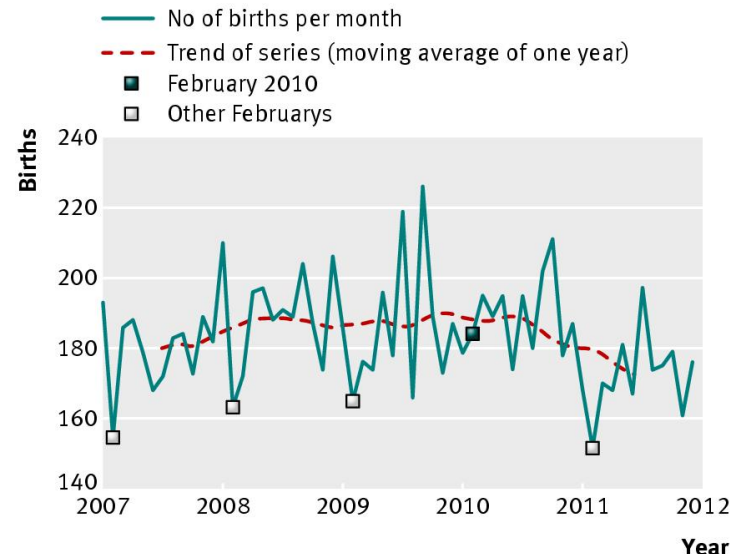

Fig 2 Number of births per month from January 2007 to December 2011 


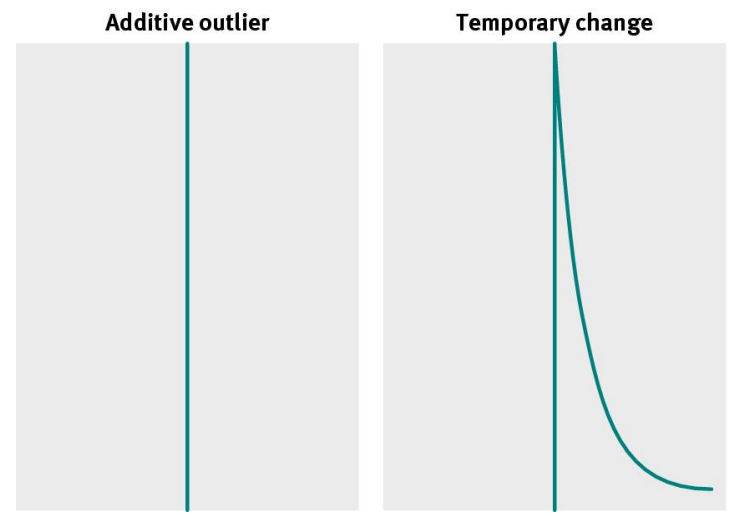

Fig 3 Types of modelling. A one-time change would reflect the Iniesta effect, while a transitory change reflects a limited but more sustained Barça victory effect

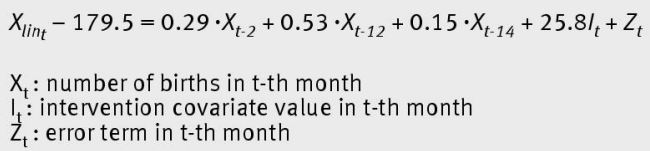

Fig 4 Barça's birthrate formula 